\title{
Hermenêutica bíblica da Teologia da Libertação
}

\author{
Hermenéutica Bíblica de la Teología de la Liberación
}

\section{Biblical Hermeneutics of Liberation Theology}

\author{
iD) Johan Konings \\ Faculdade Jesuíta de Filosofia e Teologia, Belo Horizonte, Minas Gerais, Brasil \\ konings@faculdadejesuita.edu.br
}

\begin{abstract}
Resumo: Na primeira parte aborda-se a hermenêutica bíblica em geral, vista como um diálogo entre a comunidade de autor e leitores originais com o leitor que hoje entra na roda. A oposição feita por Paulo Apóstolo entre letra e espírito serve de ponto de partida para explicar a reconfiguração hermenêutica do sentido. O "espírito" no sentido de Paulo pode ser entendido como a apropriação do sentido, que na tradição cristã pode ser chamada o "sentido pleno" da Sagrada Escritura. De passagem avalia-se, por contraste, a hermenêutica fundamentalista. Enfim descreve-se a espiral hermenêutica da interpretação do texto e da práxis. $\mathrm{Na}$ segunda parte, é evocada o afazer da hermenêutica bíblica da libertação: seu nascimento no contexto latino-americano, a experiência da leitura bíblica com o povo dos pobres, a afirmação de Jesus Cristo como critério dessa hermenêutica e as novas perspectivas que hoje se abrem a partir da hermenêutica da libertação: as leituras descolonial e ecológica.
\end{abstract}

Palavras chaves: Hermenêutica. Bíblia. Sentido pleno. Práxis. América Latina

Resumen: La primera parte aborda la hermenéutica bíblica en General, vista como un diálogo del autor y de los lectores originales con el lector que entra en la rueda hoy. La oposición del apóstol Pablo entre letra y espíritu sirve como punto de partida para explicar la reconfiguración 
hermenéutica del sentido. El "espíritu" en el sentido de Pablo puede ser entendido como la apropiación del significado, que en la tradición cristiana se puede llamar el "sentido lleno" de las Sagradas Escrituras. Al pasar se evalúa, para fines de contraste, la hermenéutica fundamentalista. Por último se describe la espiral hermenéutica de la interpretación del texto y de la praxis. En la segunda parte se evoca la elaboración de la hermenéutica bíblica de la liberación: su nacimiento en el contexto de América Latina, la experiencia de lectura de la Biblia con el pueblo de los pobres, la afirmación de Jesucristo como criterio de esta hermenéutica, y nuevas perspectivas hoy abiertas desde la hermenéutica de la liberación: las lecturas decolonial y ecológica.

Palavras Ilaves: Hermenéutica. Biblia. Sentido Ileno. Praxis. América Latina

Abstract: The first part deals with the biblical hermeneutics in general, seen as a dialogue between the original author and readers with the reader who today enters the cycle. The opposition made by Paul the Apostle between letter and spirit serves as a starting point for explaining the hermeneutic sense rewriting. The "spirit" in the sense of Paul can be understood as the appropriation of meaning, that in the Christian tradition can be called the "full meaning" of the Holy Scripture. The fundamentalist hermeneutics is evaluated by contrast. Finally, the hermeneutic spiral between interpretation of the text and praxis is described. In the second part the biblical hermeneutics of Liberation is contemplated: the origin in the Latin American context, the experience of reading the Bible with the people of the poor, the statement of Jesus Christ as criterion of this hermeneutics and new perspectives today opened out from the hermeneutics of Liberation: decolonial and ecological readings.

Keywords: Hermeneutics. Bible. Sensus plenus. Praxis. Latin America

Data de recebimento: 31/07/2019

Data de aceite: 27/09/2019 
Hermenêutica bíblica da Teologia da Libertação Johan Konings

\section{Preâmbulo}

Abordar a hermenêutica bíblica da Teologia da Libertação numa revista voltada para a Sociologia exige consciência epistemológica, pois essa hermenêutica é exercida na Teologia da Libertação no âmbito da Teologia, que é o discurso científico da experiência e da linguagem religiosa. As Ciências Sociais, fórum desta publicação, não pressupõem a fé religiosa. Isso não impede, mas antes provoca o diálogo com a Teologia, e existe considerável leitura da Bíblia na perspectiva da libertação sem o pressuposto da fé religiosa. ${ }^{1}$ Como parceira neste diálogo, a presente exposição se situa no campo da Teologia, refletindo sobre a Teologia da Libertação e contemplando os elementos socioculturais inerentes a essa reflexão. Sem pretensão de exaustividade histórica ou heurística, pretende antes ser uma reflexão intuitiva sobre a hermenêutica bíblica da libertação.

\section{Hermenêutica bíblica}

O afazer da hermenêutica bíblica foi descrito muitas vezes. $^{2}$ Não consideramos aqui as hermenêuticas que se colocam fora da tradição bíblica, mas sim aquelas que reconhecem e preservam a identidade dessa tradição. De fato, na pluralidade de interpretações, essa preocupação nem sempre está presente. Um exemplo no campo da arquitetura pode esclarecer isso. Na história da arquitetura existem casos de "reinterpretação destrutiva", por exemplo, a utilização de vestígios arquitetônicos dos templos romanos (spolia) nas construções cristãs, que procuravam obliterar a tradição pagã. Pode-se pensar também no "conflito das interpretações" ${ }^{\prime 3}$ concernente à restauração da Notre-Dame de

\footnotetext{
1 P. ex.: BLOCH, Ernst. O princípio esperança. Rio de Janeiro: EDUERJ, 2005-2006. 3 v.

2 Cf. REIMER, Haroldo; SILVA, Valmor da (org.). Hermenêuticas bíblicas: contribuições ao I Congresso Brasileiro de Pesquisa Bíblia. São Leopoldo: Oikos, 2006. Continua recomendável, aos quinze anos do falecimento do autor, a leitura de: CROATTO, José Severino. Êxodo: uma hermenêutica da liberdade. São Paulo: Paulinas, 1981; CROATTO, José Severino. Hermenêutica bíblica: para uma teoria da leitura como produção de significado. São Leopoldo: Sinodal, 1986.

3 Expressão de Paul Ricoeur em: RICOEUR, Paul. O conflito das interpretações: ensaios de hermenêutica. Rio de Janeiro: Imago, 1978.
} 
Paris depois do recente incêndio: reconstituir o telhado de madeira de carvalho e telhas de ardósia ou substituí-lo por um jardim de cobertura com piscina? Questões semelhantes apresentam-se também na hermenêutica de textos: desconstrução radical para criar um sentido totalmente novo ou cuidadosa reconstrução do sentido primeiro em circunstâncias novas? Esta última posição de continuidade - é a que procuro adotar.

Nestes últimos séculos é costume distinguir entre exegese e hermenêutica. Por exegese entende-se, então, a explicação da letra do texto segundo o sentido que se abriu para os leitores ou ouvintes originais e, por hermenêutica, o sentido que se tira do texto na atual situação de proclamação. Esse sentido hermenêutico é geralmente uma aplicação por analogia ao novo contexto da proclamação. Seja observado, porém, que essa distinção terminológica é moderna. Antigamente hermeneia, exegesis, enarratio ou outros nomes se confundiam. Isso nos adverte para não entender a distinção moderna como separação. Trata-se, antes, de dois momentos de um mesmo processo de interpretação. Tanto o leitor/ ouvinte nos albores do cristianismo quanto o do século XXI devem fazer a hermeneia do mesmo conjunto semiótico estruturado em texto que se lhes apresenta.

É verdade, porém, que ocorre um "crescimento" ou enriquecimento do texto no contínuo processo de releitura, o que será muito importante quando existir, ao longo desse processo, uma identificação que se pode chamar de tradição. Tal tradição, se ela for viva e atuante, lembrará o provérbio francês que compara a mulher à água do mar: "sempre a mesma e sempre diferente". É uma identidade-em-movimento, continuidade de "tradução dentro da tradição", ou seja, um redizer o texto de modo diferente para que diga a mesma coisa: sempre o mesmo e sempre diferente. Esse processo pode ser representado como uma equação analógica: texto I/contexto I $\approx$ texto II/contexto II. O sentido do texto no seu contexto de origem encontra uma analogia no contexto atual, e para isso é preciso que o texto seja novamente formulado (recodificado), porque a compreensão depende do contexto. 
Hermenêutica bíblica da Teologia da Libertação Johan Konings

Mudando-se o numerador da equação, deve-se mudar também o denominador: $3 / 4=12 / 16$. Para que a relação original fique conservada, é preciso reformular o texto em função da contínua mudança do contexto histórico-cultural, que fará abrir-se a "reserva de sentido".

Esta observação corta a raiz não só à desconstrução radical, mas também à interpretação literalista, que repete pura e simplesmente as palavras antigas num novo contexto, como se se pudesse manter imutável o numerador da equação quando se muda o denominador - o que falsificaria a equação. ${ }^{4}$ Repetir literalmente as palavras antigas ao procurar entendê-las num contexto novo é uma falsificação, uma traição. Em vez de traduttore traditore, diga-se ripetitore traditore.

Interpretar é necessário. A injunção "lavai os pés uns dos outros" (Jo 13,14), pronunciada por Jesus no contexto daquela ceia por volta do ano 30, se apresenta no contexto de Jo 13 como parábola do "amai-vos uns aos outros como eu vos amei" (Jo 13,34). Para ter um sentido equivalente hoje, tal frase precisa ser recodificada. Aliás, o gesto parabólico a que se refere ensejou um problema de interpretação já na origem, por parte de Pedro (Jo 13,6-10).

\section{Entrar na roda de quem puxou a conversa}

Tentemos elucidar o jogo dialético que se dá entre o sentido primeiro (na situação original de enunciação) e o sentido atualizado (em nova situação e contexto). Trata-se de uma dialética, porque o sentido primeiro revela seu potencial de sentido à medida que se abre na repetida atualização. Por isso, o papa Gregório Magno disse que o sentido do texto cresce com o leitor (Moralia in Job, 28).

Por causa dessa dialética, o exercício da hermenêutica pode ser visto como um diálogo em que o círculo de comunicação original se abre para novos participantes, os leitores/ouvintes das gerações ulteriores. Eles entram na roda de conversa onde já se

4 Neste sentido, o artigo epocal SCHWEIZER, Eduard. Orthodox Proclamation: The Reinterpretation of the Gospel by the Fourth Evangelist. Union Seminary Magazine, v. 8, n. 4, p. 387-403, Oct. 1954. https://doi.org/10.1177/002096435400800401. 
Hermenêutica bíblica da Teologia da Libertação Johan Konings

encontram - e continuam presentes - os interlocutores originários. Todavia, há uma sutil distinção entre o que o primeiro interlocutor (representado pelo "autor") quis dizer no ato da enunciação e o que ele "deixa dito" no texto - distinção entre o ato comunicativo único do passado e o texto que fica disponível para ser sempre compreendido novamente, ou seja, compreendido em novos contextos. ${ }^{5}$ A arte da "re-presentação" ou mimese hermenêutica na leitura deve permitir o desclausuramento (disclosure) daquilo que autor não disse, visto que ele não estava interagindo com o novo contexto. Decerto, quem negar a coerência entre a primeira significância e a atual poderá dispensar essa continuidade. Aquele, porém, que exerce a hermenêutica no quadro de uma tradição procurará dar conta da coerência e continuidade em meio à contínua reconfiguração. Isso vale especialmente para a tradição bíblica, em que o texto serve de "regra de fé". ${ }^{6}$ Não se pode simplesmente alegar, com certos linguistas extremos, que o autor morreu e que agora reina de modo absoluto "Sua Majestade, o texto". Antes, em companhia de Hans-Georg Gadamer, vejo a hermenêutica como um momento da tradição, em que o passado se torna presente para o hoje, no amalgamento dos horizontes da compreensão. ${ }^{7}$

Os textos bíblicos não são míticos, no sentido de evocar um conteúdo atemporal. São vestígios históricos. O desdobramento ou "ex-plicação" - pois este é o sentido do termo exegese (exagein) - de seu sentido primeiro exige que respeitemos (de re-spicere) o sítio arqueológico da conversa inicial na qual queremos entrar. Este é o papel da exegese histórico-literária, pois o vestígio é de tipo literário e é preciso conhecer a "gramática" do relato ou texto para perceber de que se trata. Não podemos ser daqueles intrometidos que roubam a palavra a quem a iniciou e a desviam para outro discurso, que não diz respeito à "coisa em causa". Por exemplo, quando Jesus comenta a lei mosaica que permitia repudiar uma mulher com a qual se estivesse casado (Mc 10,1-12 „IMt 19,3-9), não podemos nos apropriar dessa sua negativa para aplicá-la, sem

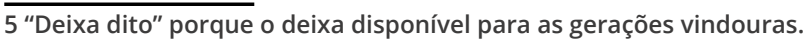

60 próprio conceito "regra de fé" é exposto a contínua reinterpretação, o que não é o caso de aprofundar aqui.

7 GADAMER, Hans-Georg. Verdade e método I: traços fundamentais de uma hermenêutica filosófica. 4. ed. Petrópolis: Vozes, 2002; GADAMER, Hans-Georg. Verdade e método Il: complementos e índice. Petrópolis: Vozes, 2002. 
Hermenêutica bíblica da Teologia da Libertação Johan Konings

mais, à problemática do divórcio em nossa sociedade. Primeiro devemos examinar se é a mesma coisa que está em causa, e isso exige um exame histórico e linguístico do texto em seu contexto histórico-cultural - a "via longa" da exegese na hermenêutica, segundo a expressão de Paul Ricoeur.

Ora, esse momento quase arqueológico do "respeitar (re-spicere) os vestígios" é delicado e deve ser literalmente circunspecto (circum-spicere), porque devemos captar, farejar o mundo em torno do texto original, que é também originante para a tradição que dele brota. Digo "mundo em torno do texto" - a distinguir do "mundo do texto" de que falarei mais adiante - para significar o ambiente histórico-geográfico-sociocultural, as circunstâncias de origem do texto que chegou até nós, com o lastro submerso que explica seus efeitos subterrâneos. Assim, ao focar no Império Romano é preciso saber que este se estabeleceu sobre a base das gentes patriciais e sobre as estruturas dos antigos impérios persa e helenista, que deixaram suas marcas, efeitos e traumas até muitos séculos depois de seu ápice. E do ambiente histórico-sociocultural fazem parte, também, o imaginário do povo, seu modo de pensar, as expectativas messiânicas, os sonhos e medos apocalípticos... Tudo isso é circunstância do texto, "mundo em torno do texto", e, quanto melhor conhecido, mais ajudará a descobrir a intenção do iniciador do texto (o "autor") e a compreensão (recepção) dos primeiros interlocutores de nosso diálogo continuado.

A hermenêutica, todavia, contemplará especificamente o "mundo do texto", isto é, o mundo interno do texto enquanto texto: nos textos narrativos, a trama ou intriga que está sendo tecida ao longo da narração; nos textos argumentativos ou retóricos, a coerência da argumentação e a estratégia do convencimento; nos textos poéticos, o mundo imaginário, em contínuo movimento, que determina a dialética de significante e significado, em que a significação se faz e se re-cria constantemente. ${ }^{8}$ Contemplará também a determinação dos campos semânticos, que permite captar qual é a "coisa" do texto, aquilo a que o texto realmente se refere

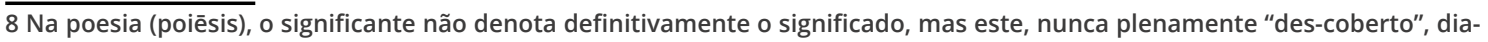
loga com os significantes que por assim dizer dele se aproximam. 
Hermenêutica bíblica da Teologia da Libertação Johan Konings

(e não aquilo que nós imaginamos ser o seu referente). Tudo isso constitui o mundo interior do texto.

No momento da hermenêutica, outro mundo ainda se apresenta: o mundo - ou os mundos - da atualidade, a nossa contemporaneidade histórico-sociocultural, assentada sobre estruturas e memórias submersas que a arqueologia do saber deve destrinchar. Também este mundo tem suas utopias e obsessões, muitas vezes inconscientes, a influenciar o significado que o leitor atual dará ao vestígio do diálogo iniciado muitos séculos antes e que no texto lhe vem ao encontro.

Mundo atrás do texto, mundo "com" o texto, ${ }^{9}$ mundo dentro do texto, ${ }^{10}$ mundo à frente do texto... ${ }^{11}$ São muitos mundos, e isso nos incita à modéstia quando tentamos interpretar um texto, pois pouco sabemos sobre o interlocutor e seus mundos, como também sobre o sujeito que nós somos e sobre os mundos presentes, passados e futuros que constituem nosso horizonte de compreensão.

Nunca se sabe demais, e a erudição não faz mal, desde que não seja causa de ufano, ${ }^{12}$ mas cabedal a serviço da interpretação que é uma diaconia da fé. Pois, com todo o respeito pelos dogmas - elementos de tradição e pontos de doutrina a serem lembrados e ensinados -, rechaçamos o dogmatismo que consiste em querer codificar definitiva e imutavelmente o significado ou em achar que determinadas codificações anteriores exprimem imutável e definitivamente o significado. O dogma não é ponto final da fé, mas antes uma baliza ao longo do caminho da interpretação continuada que, em espiral, sempre volta ao vestígio textual como ponto de partida para nova exploração de sentido.

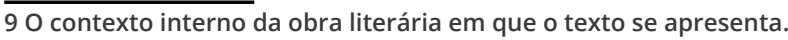

100 mundo semiótico-semântico que estrutura o texto.

110 mundo em que o texto produzirá seu efeito significativo e pragmático.

12 Cf. 1Cor 13,3, "e até entregasse meu corpo para me gloriar", lição dos melhores manuscritos, acolhida na Nova Vulgata; o Textus Receptus (tradição textual bizantina) e a antiga Vulgata liam "entregasse meu corpo para ser queimado". 
Hermenêutica bíblica da Teologia da Libertação Johan Konings

A letra e o espírito

Entre os vestígios mais antigos da tradição cristã encontra-se um belo testemunho da consciência hermenêutica: o texto de Paulo sobre a letra e o espírito. De fato, Paulo mostra que o texto bíblico em si não revela nada, é morto, mas a vida da comunidade animada pelo espírito abre seu sentido para a atualidade. Esse trecho se refere a um texto-vestígio central da própria tradição judaica de Paulo, as "tábuas da Lei", que representam a tradição toraica por inteiro. ${ }^{13}$

2 Vós sois a nossa carta, escrita em nosso coração, conhecida e lida por todos os homens, 3 estando já manifestos como carta de Cristo, produzida pelo nosso ministério, escrita não com tinta, mas pelo Espírito do Deus vivente, não em tábuas de pedra, mas em tábuas de carne, isto é, nos corações. $4 \mathrm{E}$ é por intermédio de Cristo que temos tal confiança em Deus; [...] a nossa suficiência vem de Deus, 6 o qual nos habilitou para sermos ministros de uma nova aliança, não da letra, mas do espírito; porque a letra mata, mas o espírito vivifica. $7 \mathrm{E}$, se o ministério da morte, gravado com letras em pedras, se revestiu de glória, a ponto de os filhos de Israel não poderem fitar a face de Moisés, por causa da glória do seu rosto [...], 8 como não será de maior glória o ministério do Espírito! [...] 13 E não somos como Moisés, que punha véu sobre a face [... 14...] Pois até ao dia de hoje, quando fazem a leitura da antiga aliança, o mesmo véu permanece, não Ihes sendo revelado que, em Cristo, é removido. 15 Mas até hoje, quando é lido Moisés, o véu está posto sobre o coração deles. 16 Quando, porém, algum deles se converte ao Senhor, o véu Ihe é retirado. 17 Ora, o Senhor é o Espírito; e, onde está o Espírito do Senhor, aí há liberdade. 18 E todos nós, com o rosto desvendado, contemplando, como por espelho, a glória do Senhor, somos transformados, de glória em glória, na sua própria imagem, como pelo Senhor, o Espírito. $(2 \operatorname{Cor} 3,1-18) .{ }^{14}$

13 Tradição das doutrinas referentes à Lei, ou Torá (lit. ensino/instrução/orientação).

14 Citado segundo A BíBLIA SAGRADA Antigo e Novo Testamento. Traduzida em Português por João Ferreira de Almeida. Ed. revista e atualizada no Brasil. Rio de Janeiro: sociedade Bíblica do Brasil, 1969. O grifo é nosso. As últimas palavras podem (talvez preferivelmente) ser lidas como "pelo Espírito do Senhor" (cf. Almeida "revista e corrigida", Vulgata, Nova Vulgata). 
Paulo defende sua missão de apóstolo contra os que lhe negam essa incumbência, a saber, os pregadores da Torá, que inquietam os corações dos coríntios. O ministério de Paulo afasta o véu que caracterizava o ministério de Moisés, considerado provisório, válido somente até que fosse retirado "em Cristo", na nova disposição da qual Paulo é o apóstolo. Assim, Paulo prega uma nova visão sobre a Lei ("a leitura da antiga aliança", v. 14) à luz da conversão a Cristo. Quando diz: "A nossa suficiência vem de Deus, o qual nos habilitou para sermos ministros de uma nova aliança, não da letra, mas do espírito; porque a letra mata, mas o espírito vivifica" (v. 5b-6), Paulo se refere à letra da "antiga aliança", a Torá mediada por Moisés. Paulo se considera ministro de uma "nova aliança" (Jr 31,31-33; Ez 37,26; Hb 10,16), oposta ao "serviço à morte grafado em pedras" (v. 7), que são as tábuas da Lei entregues a Moisés (Ex $31,18)$. Ora, se o "ministério da morte" exercido por Moisés era envolto de doxa, sinal da presença de Deus (Ex 34,29), tanto mais o será a diakonia tou pneumatos (v. 8), o "ministério do espírito" de que Paulo se considera encarregado. A antiga disposição não era, desde a origem, uma administração da morte - senão, a doxa de Deus não poderia envolver seu arauto Moisés. Porém, agora que chegou a plenitude da salvação em Cristo, a antiga disposição revela-se insuficiente para propiciar a vida que a fé em Cristo proporciona; portanto, não salva da morte. A explicação rabínica das Escrituras, enquanto serviço dedicado à "letra" (gramma) que Moisés exibiu no Sinai, não proporciona a vida em Cristo. Para Paulo, isso é "morte", e "viver é Cristo" (Flp 1,21). Quem, como os judaizantes atuantes no ambiente de Paulo, se atém obstinada e fanaticamente àquele sistema superado presta um serviço de morte.

Em sua condição anterior, de judeu piedoso, Paulo nunca poderia chamar a disposição mosaica de "morte". Para o mestre judeu, o serviço e estudo da Lei do Senhor (a Torá) de modo nenhum é diaconia da morte, mas caminho de luz e vida (SI 19,8-15; 119). A radicalidade da expressão de Paulo se deve à enorme reviravolta que ele viveu em sua própria vida quando, de perseguidor de Jesus 
Hermenêutica bíblica da Teologia da Libertação Johan Konings

Cristo, transformou-se em apóstolo, título que ele clama com vigor (cf. 2Cor 1,$1 ; 11,5 ; 12,12$ ).

O que nos ensina esse conflito de interpretações? Quidquid recipitur ad modum recipientis recipitur, diz o adágio escolástico: um texto ganha significação nova dependendo do "receptor" que o lê em sua circunstância, diferente da do "emissor", num distanciamento que abre espaço para a interpretação. As Escrituras de Israel, por mais que tenham sido sinal de vida para Israel e para o judaísmo, transformaram-se em sinal de morte para quem virou definitivamente as costas para o horizonte interpretativo da autojustificação pelas obras da Lei (que Paulo julga ser o de seus opositores judaizantes).

O que fez Paulo abandonar aquilo que tachou de serviço da morte é o que agora ele chama de "espírito". Este termo é uma metáfora. Os referentes primordiais deste significante são o vento e o sopro, forças que de modo invisível movimentam objetos inanimados e dinamizam os seres vivos: "Retiras teu espírito, desvanecem. [...] Envias teu espírito, são criados" (SI 104,29-30). Na semântica bíblica, "espírito" aponta, muitas vezes, a disposição da pessoa, seu bom ou mau espírito. Na semântica helenística, o termo pode evocar a constituinte invisível e imaterial do ser humano: a alma, o intelecto. Na Cristandade e na cultura burguesa, vai significar ora a piedade (a "espiritualidade"), ora a sensibilidade e inteligência refinadas, até no lluminismo se tornar sinônimo da Razão (Hegel!). Por outro lado, a partir dos sentidos bíblico e helenístico desenvolve-se, na teologia cristã, o sentido trinitário de "Espírito" indicando a terceira Pessoa da Santíssima Trindade como sujeito do atuar divino na indivisível unidade de Deus. ${ }^{15}$

A semântica paulina de "espírito" tem suas raízes no ambiente bíblico. Quando Paulo fala de "espírito" indica, principalmente, o espírito do Senhor Jesus e do Deus vivo (cf. 2Cor 3,3). Esse espírito se manifestou nos profetas de Israel e em Jesus de Nazaré, sobretudo em sua ressurreição $(\mathrm{Rm} 1,4)$. Ele impulsiona também os

15 Nas discussões trinitárias houve oscilação entre os termos hypostasis e prosōpon, em latim substantia e persona, mas o primeiro não podia ser aplicado às pessoas da Trindade porque podia ser sinônimo de ousia, que significava a única natureza divina. 
seus apóstolos, entre os quais o próprio Paulo. É derramado nos fiéis, inclusive em forma de dons e capacidades admiráveis (1Cor 12,4 etc.; cf. At 2,4).

No texto destacado, Paulo menciona, em linguagem abreviada, o Espírito como ação de Deus: "O Senhor [= Deus, Adonai] é o Espírito" (2Cor 3,17). A ação de Deus nos dá liberdade em relação a uma interpretação ultrapassada da própria manifestação de Deus que é a Torá, confiada a Israel por intermédio de Moisés.

Assim, "a letra mata, o espírito vivifica" significa que, no sistema hermenêutico judaico, as Escrituras ficam sem produzir vida. Ao contrário, quando lidas e interpretadas no espírito de Jesus Cristo, que anima o apóstolo e sua comunidade, produzem vida. O Espírito produz a liberdade de interpretar a Lei sem véu. Para Paulo, o espírito da leitura é Deus agindo.

\section{"Espírito" como apropriação do sentido}

A "letra" é o texto que deve ser examinado em sua condição histórica e literária. A abordagem histórica nos mostra como e em que contexto, em quais condições e mediante que processo esses textos nasceram. Na abordagem literária perscrutamos os percursos narrativo, poético e retórico pelos quais o texto conduz o leitor. Na abordagem semântica verificamos qual significado o texto gera/produz, levando em consideração sua estrutura semântica. Mas enquanto tudo isso não for apropriado pelo leitor, é material morto, que só se faz vivo quando o leitor o assume dentro do sentido vital que vai construindo.

Tal assumir como sentido vital é o que eu gostaria de entender pelo termo "espírito" em 2Cor 3,6. No quadro de uma reflexão mais ampla sobre a hermenêutica bíblica cristã, o espírito está intrinsecamente ligado à adesão a Jesus de Nazaré no seio de sua comunidade, a qual se estende horizontal e verticalmente, ou seja, na contemporaneidade (sincronia) de cada momento histórico e na transtemporalidade (diacronia) de sua história enquanto tra- 
Hermenêutica bíblica da Teologia da Libertação Johan Konings

dição. Proponho, pois, que se entenda por "espírito que vivifica" (2Cor 3,6$)$ não algum misterioso dom de êxtase, mas a contribuição concreta e historicamente situada, com efeito trans-histórico, da comunidade e da tradição viva, em que a letra é vitalmente apropriada pelo cristão, pessoal e comunitariamente (pois estas duas dimensões são inseparáveis).

\section{O sentido pleno}

Voltemos a Gregório Magno: o texto cresce com o leitor. Isso se deixa ilustrar pela leitura bíblica patrística e medieval. Aí não existe um sentido único de um texto. ${ }^{16}$ Os textos bíblicos são tratados como sendo de interpretação aberta, ${ }^{17}$ permitindo sentidos analógicos, com base na semelhança significativa com o sentido que se costuma chamar literal. Segundo Henri de Lubac, ${ }^{18}$ a teologia medieval distinguia, além do sentido literal (que já em si pode ser figurativo, p. ex., nas parábolas, nas imagens poéticas etc.), diversos sentidos analógicos, chamados de sentido alegórico ou espiritual, aplicados aos mistérios de Cristo, da Igreja, dos santos, à vida moral etc. Criou-se a didática - método de compreensão e ensino - dos "quatro sentidos da Escritura": o histórico (intencionado pelo autor em seu contexto), o alegórico (no sentido de imagem-suporte para os elementos da tradição cristã), o tropológico (moral-dogmático) e o anagógico (salvífico). Na realidade, estes três últimos sentidos são todos figurativos ou tipológicos, baseados em determinada analogia ou semelhança, a qual pode ser mais externa (p. ex., a assembleia do povo judeu e a igreja cristã, o cordeiro imolado e o Cristo crucificado) ou mais interna (p. ex., as virtudes do príncipe messiânico em Is 11,2 e os dons do Espírito Santo). Henri de Lubac ressalta a dimensão cristológico-escatológica (Jesus Cristo trouxe em Si a salvação definitiva, o eschaton). Podemos chamar isso de "sentido pleno", pois exprime a potencialidade significativa última (para determinada intenção

\footnotetext{
16 A não ser que ele seja exclusivamente definitório ou denotativo, independentemente do contexto, como na matemática e nas ciências exatas (na medida em que são exatas...).

17 A poiēsis de Ricoeur.

18 Seu pensamento encontra-se resumido em: LUBAC, Henri de. A Escritura na tradição. São Paulo: Paulinas, 1970.
} 
Hermenêutica bíblica da Teologia da Libertação Johan Konings

de compreensão) do significante primeiro. Isso é importante para a compreensão das citações e alusões ao Antigo Testamento no Novo, amiúde apresentadas como "cumprimento" (no sentido de plenificação) das Escrituras.

Existem, no Novo Testamento, certos textos que representam o sentido pleno do Antigo de modo bastante literal, como, por exemplo, Mt 21,2-7. Neste, usando uma imagem de Zc 9,9, Mateus descreve Jesus entrando em Jerusalém "montado num asno e num jumentinho, filho de jumento" (Mt 21,5, trad. literal). Segundo os cânones da poesia hebraica, o texto de Zacarias é um paralelismo: não trata de dois animais, um jumento e um asno, mas de um jumento, um jumentinho até! Coisa semelhante se dá na citação de Salmo 22,19 em Jo 19,24, a repartição das roupas de Jesus e a rifa do manto em quatro partes, uma para cada soldado, "para que se cumprisse a Escritura: Repartiram minhas vestes entre si e sobre meu manto lançaram a sorte". ${ }^{19}$ Conhecendo a fineza desses dois evangelistas, devemos pensar que se trata antes de artimanha literária do que de descrição histórica. Eles não procuram oferecer uma descrição realista, mas reproduzem o paralelismo poético do texto veterotestamentário com toda a literalidade para fixar a imagem e seu sentido pleno mais profundamente na mente do leitor.

As citações e alusões escriturísticas, de modo geral, exprimem que em Jesus - em pessoa ou na comunidade unida a ele - aquilo que ouvimos nas antigas Escrituras recebe um sentido novo e plenificado, que doravante alimentará nossa contemplação do mistério de Cristo. Para isso não é preciso que se realizem literalmente as palavras antigas, mas que falem de Cristo e de sua obra. Aliás, o que os profetas disseram geralmente não é predição, pois um profeta não é um futurólogo, mas um porta-voz de Deus acerca da realidade que ele tem diante dos olhos, passada, presente ou futura.

O sentido pleno não é o fechamento absoluto da produção de sentido. É como um dogma: uma baliza indicando o caminho

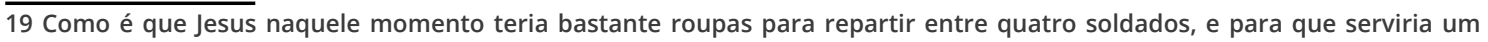
manto repartido em quatro partes? 
Hermenêutica bíblica da Teologia da Libertação Johan Konings

para ir adiante. Quem acolhe o sentido pleno julga que, para si, o respectivo texto escriturístico - sob o aspecto no qual ele é visto - aponta para Cristo, e a partir daí podem eclodir outras significações.

\section{Métodos, leituras e fundamentalismo}

Cabe aqui uma palavra sobre o fundamentalismo. De fato, em nossas assembleias, uma leitura fundamentalista mistura-se com o que deveria ser o contrário, a leitura "espiritual" (no supraexposto sentido de Paulo). Um bom panorama dessa questão foi apresentado pela Pontifícia Comissão Bíblica da Igreja Católica no ano de 1993, esclarecedor também para as outras igrejas cristãs: "A interpretação da Bíblia na Igreja".20

No capítulo I, o texto fala dos métodos e abordagens para a interpretação da Bíblia: (A) o método histórico-crítico; (B) os novos métodos de análise literária (sincrônicos): análise retórica, narrativa, semiótica; (C) as abordagens (não métodos!) baseadas na Tradição: a abordagem canônica, a abordagem voltada para a tradição judaica, a abordagem através dos efeitos do texto; (D) as abordagens através das Ciências Humanas: sociológica, antropológico-cultural, psicológica e psicanalítica; (E) as abordagens contextuais: da libertação, feminista; e, por último, (F) a leitura fundamentalista, a única que não recebe nenhuma recomendação, mas é criticada porque se pretende isenta de qualquer interpretação.

Cabe distinguir entre o fundamentalismo original da conferência de Niagara em 1910 (que define cinco verdades bíblicas que devem ser tomadas literalmente) ${ }^{21}$ e o fundamentalismo lato sensu (que leva qualquer frase ao pé da letra e, além disso, produz fanatismos semelhantes aos que se revelam no islamismo fundamentalista) ${ }^{22}$. O problema do fundamentalismo lato sensu

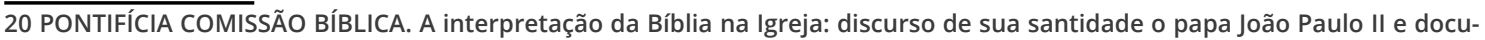
mento da Pontifícia Comissão Bíblica. 7.ed. São Paulo: Paulinas, 2006.

21 Niagara Bible Conference. Disponível em: http://www.thearda.com/timeline/events/event 93.asp. Acesso em: 27 set. 2019. Também: KONINGS, Johan. Fundamentalismo bíblico-teológico-religioso. In: MILLEN, Maria Inês de Castro; ZACHARIAS, Ronaldo (org.). Fundamentalismo: desafios à ética teológica. Aparecida SP: Santuário, 2017, p. 173-174.

22 Ampla bibliografia em: INTROVIGNE, Massimo, O fundamentalismo: das origens ao Estado Islâmico. São Paulo: Loyola, 2019.
} 
é a pretensa rejeição de interpretação, o que não deixa de ser uma interpretação, a saber, a que considera certos textos bíblicos como se fossem afirmações puramente denotativas, como as fórmulas matemáticas. Isso leva a uma absolutização, por exemplo, do Antigo Testamento, prescindindo do sentido plenificado que ele recebe no novo contexto que se produziu a partir de Jesus de Nazaré. Resultado disso é que certos cristãos continuam prescrevendo práticas do Antigo Testamento como se Jesus nunca tivesse existido. Se existe, por exemplo, um fundamentalismo do dízimo (baseado em Lv 27,30), por que então não manter também a circuncisão? O fundamentalismo absolutiza o escrito, sem levar em consideração que o escrito é a expressão de uma vivência contextual e histórica conduzida - acreditamos - pelo Espírito de Deus. Acaba por submeter não só os homens, mas também Deus ao texto escrito, à "letra". Bem diferente de Jesus, que citou como bom exemplo a atitude de Davi, que fez os seus soldados se alimentarem com os pães sagrados do santuário, reservados aos sacerdotes (Mc 2,25-26).

\section{A espiral hermenêutica}

Assumir o sentido novo que se abre quando se entra em diálogo com o texto tem seus efeitos históricos. O texto é o vestígio dos interlocutores da primeira hora. Transmitido a partir deles, o texto volta à vida não somente no novo significado que se torna presente, mas também na nova práxis que o assumir implica. "Felizes sois se compreenderdes isso e o puserdes em prática", diz Jesus depois do lava-pés (Jo 13,17). A verdade da compreensão é a práxis. Por isso João usa a expressão "fazer a verdade" (Jo 3,21). A verdade não é real se ela não se traduz na prática. Quem diz saber dirigir o carro, mas na primeira curva o reduz a frangalhos é um mentiroso. A práxis faz parte do sentido, é a objetivação do sentido (um pouco como Hegel distinguia o espírito subjetivo e o espírito objetivo). A práxis torna real o conceito concebido pelo sujeito. 
Hermenêutica bíblica da Teologia da Libertação Johan Konings

A partir daí, a nova práxis realizadora da compreensão hermeneuticamente ampliada cria novas circunstâncias, um novo mundo ambiente para o texto, portanto, provoca nova hermenêutica. Ao mesmo tempo, o texto vai revelando um novo potencial pela compreensão hermenêutica que Ihe foi aplicada, compreensão essa que encontrará sua verdade (no sentido de realidade) na prática (enquanto práxis consciente de seu sentido). E assim se estabelece a espiral da contínua reinterpretação da letra na práxis e da práxis na teoria, dentro da mesma tradição.

"A casa nunca está acabada"... A "signi-ficação" (o "fazer sentido") nunca está acabada. ${ }^{23} \mathrm{O}$ sentido está sempre aberto. A hermenêutica não se deixa captar num pensamento universal acabado. É um diálogo sem fim, assim como o dogma não é a palavra final, mas o reconhecimento ou fixação contextual de uma sentença como baliza orientadora na história da interpretação e, neste sentido, a primeira palavra de um enriquecimento anteriormente não afirmado, mas doravante inspirador para a continuação do diálogo.

\section{A hermenêutica latino-americana da libertação}

A hermenêutica bíblica da libertação no contexto latino-americano

Toda hermenêutica é, por definição, particular, não universal, porque põe um leitor/ouvinte em diálogo com outro, tendo ambos uma experiência particular. Uma hermenêutica universal seria o fim do diálogo e da hermenêutica. A hermenêutica da libertação é uma hermenêutica particular, provocada pelo contexto latino-americano, sem excluir as hermenêuticas surgidas em outros contextos semelhantes, como, por exemplo, a recente hermenêutica descolonial.

Falamos aqui sobre a hermenêutica do tema bíblico da libertação no contexto do pensamento que ganhou o nome de Teologia

23 Assim soava, em língua neerlandesa, o título original da obra de Vergote: VERGOTE, Antoon. Liberare dio, liberare l'uomo. Assisi: Cittadella, 1977. 
Hermenêutica bíblica da Teologia da Libertação Johan Konings

da Libertação, a qual tem um laço muito especial com o afazer teológico na América Latina. Não se trata de uma hermenêutica qualquer, de uma libertação qualquer! Digo isso porque, em determinado momento, o "sucesso" da Teologia da Libertação tem provocado a utilização desse nome até em sentido oposto ao original.

Consideraremos, pois, a hermenêutica do tema "bíblico" da libertação em função da situação específica que fez eclodir essa temática na América Latina e também em outros países do Terceiro Mundo. O surgimento dessa hermenêutica não pode ser desvinculado da história mundial depois da Segunda Guerra Mundial. Durante as décadas da reconstrução pós-guerra, o mundo passou por profundas mudanças, não só na dimensão material, econômica e política, mas também cultural e espiritual. Por um lado, consolidaram-se os dois blocos político-econômico-militares, a União Soviética e o pacto do Atlântico Norte (EUA e Europa Ocidental), criando a situação de "guerra fria". Por outro lado, as instituições políticas da primeira metade do século XX passaram por profundas transformações. Na Europa Ocidental, as ditaduras que haviam sobrevivido à guerra (Espanha, Portugal) tendiam lentamente ao declínio. Em todos os países cresceu o projeto do Estado de Bem-Estar (Wellfare State), suavizando, nas social-democracias, o capitalismo do início do século XX pelo socialismo keynesiano, que também servia de escudo contra o comunismo. ${ }^{24}$ Ao mesmo tempo, as colônias europeias na Ásia e na África - em parte por terem fornecido tropas para a guerra - perceberam a possibilidade de se declararem independentes, inclusive as colônias portuguesas Moçambique e Angola em 1975. E no meio disso houve a epopeia de Cuba enfrentando os EUA e as lutas de libertação socioeconômica na América Central e Meridional (Colômbia, El Salvador, Nicarágua....).

Criou-se, assim, um clima em que os termos "libertação" e "comunidade" se tornaram palavras-chaves entre os intelectuais e ativistas conscientizados e também nos grupos populares que tomaram consciência de que a opressão que sofriam não era

24 John Maynard Keynes escreveu já em 1936, depois da grande crise Americana, a “Teoria Geral do Emprego, do Juro e da Moeda" e, em 1944, na Conferência de Bretton Woods, tornou-se fundador do Fundo Monetário Internacional (FMI). 
Hermenêutica bíblica da Teologia da Libertação Johan Konings

nem inevitável, nem vontade divina. Ao mesmo tempo, a nascente consciência ecológica questionava os modos de exploração industrial-capitalista, e o insucesso do Ocidente na guerra do Vietnã questionava a supremacia do mundo capitalista. Essa conexão com as mudanças em nível mundial explica que os movimentos libertários na América Latina - sem esquecer o Movimento Negro nos EUA - atraíram a atenção do mundo inteiro, sobretudo quando, em consequência da reação autoritária e repressiva em diversos países, estudantes e intelectuais latino-americanos afluíram maciçamente às universidades europeias.

Nesse contexto ocorreu o Concílio Ecumênico Vaticano II (1962-1965), que dizia respeito em primeiro lugar à Igreja Católica, mas abriu sua perspectiva às igrejas cristãs em geral, a tal ponto que o termo "ecumênico" logo ultrapassou sua semântica canônica (os bispos católicos do mundo inteiro) e ficou sugerindo o diálogo com todas as igrejas cristãs, como assinalaram os convites aos respectivos observadores. ${ }^{25}$ Também recebeu impulso o "macroecumenismo" (o diálogo inter-religioso), ${ }^{26}$ estendendo-se até o diálogo com o ateísmo e contribuindo para a superação do anticomunismo cultivado até então.

Num primeiro momento, o Concílio tinha sido apresentado como continuidade ou complementação do Concílio Vaticano I - interrompido pela guerra franco-alemã e a unificação da Itália em 1870 -, especialmente quanto à colegialidade dos bispos. Logo, porém, mostrou-se a necessidade de respostas teológicas e pastorais para os desafios das enormes mudanças da época: no Primeiro Mundo, a secularização, e no Terceiro Mundo, a busca de uma nova ordem político-social e econômica. Às vezes se diz que o Concílio privilegiou as questões do Primeiro Mundo - a secularização -, de modo que a América Latina teve de esperar sua recepção na II Conferência do Episcopado Latino-Americano em Medellín (1968). Mas não se deve exagerar essa distinção, pois a Teologia da Libertação, desenvolvida sobretudo na América Latina, não é

25 Entre os quais se destacam os teólogos protestantes Karl Barth e Oscar Cullmann. 26 Importância de Gandhi, do Dalai-Lama e de diversas figuras do mundo islâmico. 
Hermenêutica bíblica da Teologia da Libertação Johan Konings

alheia ao pensamento secular e à autonomia das realidades terrestres presentes, discretamente, na Lumen gentium e, com toda a clareza, na Gaudium et spes. ${ }^{27}$ Por outro lado, foi no âmbito do Concílio que nasceu a opção pelos pobres como compromisso de uma parte considerável do episcopado latino-americano, a saber, no Pacto das Catacumbas. ${ }^{28}$

Aspecto importante da Teologia da Libertação é seu caráter prático, inerente à sua epistemologia, porque a verdade do Evangelho está na prática, e esta se realiza numa vida comunitária que encarne a opção pelos pobres..$^{29} \mathrm{As} \mathrm{comunidades} \mathrm{de} \mathrm{base} \mathrm{são,}{ }^{30}$ por assim dizer, o laboratório ou viveiro desta teologia. O nome de "libertação" corresponde ao contexto latino-americano por causa de dupla referência histórica: a libertação da colônia no início do século $\mathrm{XIX},{ }^{31}$ e a libertação dos escravos no fim daquele século. ${ }^{32}$ Por outro lado, apesar de lembrar a epopeia de Bolívar, a "libertação" de que fala a Teologia da Libertação nada tem a ver com a liberdade liberal, que coloca o indivíduo em primeiro lugar, assim como nada tem a ver com o uso do termo nas celebrações de "cura e libertação". ${ }^{33}$ A libertação que marca a teologia desenvolvida a partir do Vaticano II não deve ser vista como sendo apenas uma libertação "de" (algum mal pessoal ou da opressão político-econômica, sem mais), mas como libertação "para" a práxis comunitária enquanto encarnação histórica do Reino de Deus anunciada como boa-nova por Jesus de Nazaré - de onde o interesse central do Jesus histórico. ${ }^{34}$

\footnotetext{
27 Julgava-se que a questão da libertação sociopolítica já era suficientemente polêmica e que não convinha acrescentar a questão da secularização. Contudo, teria sido proveitoso se a Teologia da Libertação tivesse articulado com mais clareza sua inerente dimensão de pensamento secular, para evitar, por um lado, o perigo de indevida sacralização de determinada visão sociopolítica e, por outro, situar-se com maior adequação no espaço da "teologia pública".

28 Cf. BEOZzo, José Oscar. Pacto das Catacumbas: por uma Igreja servidora e pobre. São Paulo: Paulinas, 2016.

29 Pode-se interpretar neste sentido o texto de 1Jo 3,18.

30 Que em outros continentes têm outros nomes, entre os quais o mais sugestivo, grassroots.

31 Lembrado também na "Copa dos Libertadores".

32 No Brasil, abolição da escravatura, 13 de maio de 1888. No Haiti, os escravos que se revoltaram em 1791 declararam, como primeiro povo de toda a América Latina, a independência em 1804.

33 Praticadas nos movimentos evangélicos neopentecostais e católicos carismáticos.

34 Por isso não basta ver no "Cristo Libertador" um zelote ou rebelde, mas aquele que inaugura a nova comunidade do Reino de Deus.
} 
Hermenêutica bíblica da Teologia da Libertação Johan Konings

Leitura da Bíblia com o povo dos pobres

A partir da Conferência de Medellín e de outros pronunciamentos e eventos nos primórdios do pós-Concílio, e com a influência dos movimentos e métodos da educação popular, nasceu a larga onda da "leitura bíblica popular" ou "leitura da Bíblia com o povo". E não se deve esquecer a tradição evangélica ou protestante que, desde suas origens na Europa e sua implantação nas Américas, promoveu a leitura generalizada da Bíblia, até como método de alfabetização, ${ }^{35}$ embora nem sempre na óptica do povo oprimido e, menos ainda, de sua libertação "secular". ${ }^{36}$ Ora, é precisamente aí que surge a questão da libertação. Não basta o povo simples ler a Bíblia e eventualmente, mediante a alfabetização e a educação assim adquiridas, subir um degrau numa sociedade que continua classista e racista. Sem a opção pelo povo oprimido, esse tipo de leitura bíblica pode até tornar-se fonte de acomodação ou mesmo de pretensa superioridade em relação ao povo oprimido. Não basta proporcionar aos pobres a leitura da Bíblia. Eles devem descobrir que a Bíblia fala da vida deles e de seus irmãos, e que, nas situações de opressão e injustiça, o Deus da Bíblia está no lado dos oprimidos também nas suas lutas em nível histórico e secular. Trata-se de fazer com que o povo seja o sujeito de uma leitura que lê na Bíblia sua própria vida. ${ }^{37} \mathrm{~A}$ hermenêutica da libertação é sustentada, portanto, pela leitura na óptica do pobre e, mais do que isso, pela opção pelos pobres em meio à opressão, colocando-se ao lado deles. ${ }^{38}$

É preciso, todavia, ter clareza epistemológica neste ponto. Numa formulação incompleta se diz, às vezes, que o pobre é o centro da Teologia da Libertação. Isso tem provocado certa reação insistindo em que o centro da teologia cristã é Deus e seu enviado Jesus, como Messias e Filho de Deus. Por isso será melhor

\footnotetext{
$35 \mathrm{Na}$ Igreja Reformada da Holanda (calvinista), saber ler era quase uma condição para ser membro da comunidade. Lógico: o único magistério era a Bíblia.

36 A Teologia da Libertação deve contemplar a libertação política, que é secular, mas com os olhos da fé.

37 Cf. MESTERS, Carlos. Por trás das palavras: um estudo sobre a porta de entrada no mundo da Bíblia. 2. ed. Petrópolis: Vozes, 1975; MESTERS, Carlos. Flor sem defesa: uma explicação da Bíblia a partir do povo. 3. ed. Petropolis: Vozes, 1986.

38 Quando perguntaram a D. Ivo Lorscheiter se isso não significava a exclusão dos ricos, ele respondeu: “De modo nenhum, é só os ricos se colocarem ao lado dos pobres..." (memória oral).
} 
Hermenêutica bíblica da Teologia da Libertação Johan Konings

dizer que o pobre, enquanto pobre e por ser pobre, determina o ângulo de visão assumido pela teologia parcial que é a Teologia da Libertação. Ele é o "lugar teológico" e por isso ele está no foco da atenção teológica, mas o critério do olhar teológico cristão é Jesus Cristo. Seja lembrado o método da JOC, ${ }^{39}$ o Ver-Julgar-Agir: o "ver" se refere ao objeto da análise, o pobre enquanto pobre - e, por causa da importância desse objeto, a análise não pode ficar na superficialidade, mas deve lançar mão dos métodos proporcionados pelas ciências sociológicas, históricas e outras; o "julgar", para ser teológico e cristão, deve ter Cristo como critério, para que o "agir" se realize "em Cristo", em comunhão com Cristo e com os que Ihe pertencem.

\section{O critério: Jesus Cristo e seu Deus}

O Deus de Abrãão e de Jacó é também o Deus de Jesus Cristo. ${ }^{40}$ Não basta invocar Deus, é preciso que o deus invocado seja o Deus que Jesus chama de Pai. Na plena compreensão de Deus, o "Terror de Isaac" (Gn 31,42) deve ser entendido como o Pai de Jesus no seu júbilo messiânico (Lc 10,21-22 ||Mt 11,25-27), ${ }^{41}$ no seu clamor do Getsêmani (Mt 26,39) e na sua autodoação na cruz (Lc 23,46).

Para um cristão, o critério do reconhecimento do agir divino se encontra no sintagma "em Cristo". Nem sempre a Bíblia é lida "em Cristo" pelos que se chamam cristãos. Causa até perplexidade ver certo tipo de insistência no dízimo (baseada numa questionável interpretação do Levítico $)^{42}$, se nas palavras de Jesus este tema só é mencionado duas vezes, como elemento do ufano farisaico (LC 11,42\|Mt 23,23, e Lc 18,12). Cristo é a plenitude da Lei (Rm 10,4). João não prescreve um mandamento novo, mas o antigo se torna "novo e verdadeiro em Cristo e em vós" (1Jo 2,8). Nosso julgamento ético se torna novo e pleno em Cristo. Isso é um critério

39 A JOC-Juventude Operária Católica, fundada entre as duas Guerras Mundiais pelo padre Joseph Cardijn, criou esta pedagogia, que depois foi adotada também por outros setores da Ação Católica especializada.

40 Expressão de Blaise Pascal (Pensamentos, 14, 7).

41 Cf. TORRES QUEIRUGA, Andrés. Do terror de Isaac ao Abba de Jesus: por uma nova imagem de Deus. São Paulo: Paulinas, 2001.

42 Em Lv 27,30, "todos os dízimos da terra" se refere às terras dos israelitas, não à Terra no sentido planetário. 
Hermenêutica bíblica da Teologia da Libertação Johan Konings

importante na leitura libertadora da Bíblia. Não podemos, depois da cruz de Cristo, invocar o "Terror de Isaac" (Gn 31,53). A práxis de Jesus Cristo é o "sentido pleno" das "libertações" operadas por Deus (Adonai, Shaddai etc.) no Antigo Testamento, entre as quais a libertação dos hebreus do Egito. A Carta Magna de Jesus, o Sermão da Montanha, que inicia com a bem-aventurança dos pobres e dos aflitos, ${ }^{43}$ dá à Lei o seu sentido pleno (Mt 5,17-19) porque tem como centro o amor gratuito que se verifica com a maior clareza no amor ao inimigo ( $\mathrm{Mr}$ 5,43-48||Lc 6,27-28.32-36), ilustrado também na parábola do Samaritano (Lc 10,25-37) e definitivamente atestado na hora da cruz.

Alguns temas devem ser interpretados com cuidado a partir dessa perspectiva. Quando no Novo Testamento reaparece tema veterotestamentário da militância, nada tem a ver falanges e pseudo-milícias, mas significa a militância com as armas da fé e do amor, citada em toda a prístina literatura cristã. ${ }^{44} \mathrm{~A}$ terminologia da luta não deve ser rechaçada, ${ }^{45}$ mas interpretada "em Cristo". Um tema delicado é o do sofrimento, que facilmente pode ser interpretado de modo alienante. A isso se responde que, por um lado, o sofrimento não é o que Deus deseja, mas, por outro lado, pode se tornar a "vontade" de Deus se for como instrumento do amor, "em Cristo". O Novo Testamento vê o sofrimento de Cristo como instrumento de resgate e assume a ideia do sofrimento substitutivo. Porém, em vez de fazer disso um paradigma de passividade, a leitura libertadora relê o tema como significando a "com-paixão" com os oprimidos e sofredores e como apelo a descê-los da cruz. ${ }^{46}$ Do mesmo modo, a temática do "sacrifício (de expiação)" recebe em Cristo um novo sentido, de superação dos sacrifícios rituais do Antigo Testamento pela livre disposição para servir aos irmãos (Hb 10,7.9).

\footnotetext{
43 Qualificados em Mt 5,3 como “no (ou: pelo/quanto ao) espírito”, mas isso não se refere a pobres no sentido meramente espiritual, e sim a pobres reais (ptōkhoi, lit. "no chão"), confiantes no Senhor, como os rebaixados e quebrantados de coração de Is 57,$15 ; 61,1$; Sf 2,3 etc. Os "pobres" do v. 3 estão em paralelo com os "aflitos" (penthountes) do v. 4 (temas do Segundo Isaías). 440 melhor exemplo é Ef 6,13-16, que se inspira de Is 59,17; 11,5 e outros textos veterotestamentários.

450 gênero literário "agônico" (do grego agōn, “luta, combate”) tem diversas configurações, referentes sobretudo ao combate de guerra e à competição no estádio.

46 Cf. MOLTMANN, Jürgen. El Dios crucificado: la cruz de Cristo como base y crítica de toda teología cristiana. Salamanca: Sigueme, 1975; MOLTMANN, Jürgen. O caminho de Jesus Cristo: cristologia em dimensões messiânicas. Petropolis: Vozes, 1993. SOBRINO, Jon. Cristologia a partir da America Latina: esboco a partir do seguimento do Jesus histórico. Petrópolis: Vozes, 1983.
} 
Hermenêutica bíblica da Teologia da Libertação Johan Konings

O paradigma da leitura libertadora tem sido, antes de tudo, a libertação de todas as formas de escravidão e de opressão - política, socioeconômica, cultural, de gênero, por parte de instâncias alheias ao "povo de Deus" ou mesmo atuantes no meio dele (reis, sacerdotes...). O mesmo paradigma abre também os olhos para estruturas opressoras até dentro da própria comunidade cristã. Tudo isso é valioso, mas parece que se deve aprofundar mais. Quem é o Jesus Cristo Libertador? O Jesus histórico ou o Cristo da fé? Facilmente se procura o Jesus histórico, de preferência nos evangelhos sinópticos, vendo-o como revolucionário, quiçá zelota, ${ }^{47}$ ou como sábio, alternativo, ${ }^{48}$ ou algo assim. Com certeza, a mais antiga tradição guarda a memória de "Jesus Cristo vindo em carne" como diz o autor joanino em 1Jo 4,2. Porém, para o mesmo autor, essa carne "jesuana" é "a Palavra (de Deus)" (Jo 1,14). A busca do Jesus histórico deve ser entendida como a busca da Palavra de Deus na práxis de Jesus, mas só a fé percebe a plenitude dessa Palavra, a partir da glorificação, que é o "enaltecimento" na cruz, confirmado pela ressurreição e pelo dom do Espírito. ${ }^{49}$

Resumindo: o foco da leitura ou hermenêutica libertadora é o pobre, focalizado a partir do seu ponto de vista (a óptica do pobre), à luz do critério que é o Cristo morto e ressuscitado.

Novas hermenêuticas são possíveis e necessárias

O próprio caráter analógico da hermenêutica da libertação nos permite, e até nos convida, a estender sua visão a outros paradigmas que não somente os sociopolítico-econômicos. Parece não só possível, mas necessário desenvolver novas hermenêuticas "libertadoras" para a América Latina e para todos os setores atingidos pelas atuais formas de exploração na sociedade global, como mostram as preocupações do Papa Francisco. Pensamos especialmente na hermenêutica descolonial e na hermenêutica ecológica.

\footnotetext{
47 ASLAN, Reza. Zelota: a vida e a época de Jesus de Nazaré. Rio de Janeiro: Zahar, 2013.

48 CROSSAN, John Dominic. O Jesus histórico: a vida de um camponês judeu do Mediterrâneo. Rio de Janeiro: Imago, 1994. 49 Isso se exprime sobretudo na teologia joanina (p. ex., Jo 12,31-33).
} 
Hermenêutica bíblica da Teologia da Libertação Johan Konings

A hermenêutica descolonial se impõe porque, mesmo dois séculos depois de Bolívar, o espírito colonial continua presente na mente de muitos latino-americanos, "pequenos e grandes" - e esta observação pode ser estendida, por analogia, a muitas outras regiões do mundo globalizado neste início de século XXI. ${ }^{50}$ Oficialmente, esses países (em sua maioria) não são mais colônias, mas o colonizador continua presente, interna e externamente. Externamente, na forma das corporações transnacionais que exploram o Terceiro Mundo, agora chamado "emergente", do mesmo modo como fizeram as antigas potências coloniais e com a evidente cumplicidade de algumas nações dominantes de hoje, contando com a legitimação fornecida por ideologias e teorias socioeconômicos concebidas em função da modernidade homogeneizadora e centralizadora. Internamente, na mentalidade e na prática das elites que consideram os países como sua propriedade particular, mas também na cabeça dos populares que consideram necessário submeter-se - eventualmente para subir de classe - ao sistema assim estabelecido nos sucessivos pactos coloniais.

A função principal do pensamento descolonial é enfrentar o pensamento colonial introjetado na cabeça das pessoas, inclusive dos pobres, como mostram, por exemplo, as recentes campanhas eleitorais e a subserviência aos dominadores do atual pacto colonial. ${ }^{51}$ Essa introjeção tem dois lados. Por um lado, as elites "altas e baixas" introjetaram, muitas vezes inconscientemente, a mentalidade dos senhores coloniais. É impressionante ver como certa pequena e média classe média, muitas vezes de ascensão recente, entrou na lógica da meritocracia e se colocou, imaginariamente, no pedestal dos que se consideram os únicos a trabalharem de verdade. Por outro lado, há os eternos pobres do Brasil, que introjetaram a submissão escravista no onipresente "complexo de vira-lata", impossibilitando qualquer transformação profunda da assim chamada "alma brasileira". Por isso, o pensamento teológi-

\footnotetext{
50 Cf. MIGNOLO, Walter D. La idea de América Latina: la herida colonial y la opción decolonial. Barcelona: Gedisa, 2014 e KUZMA, César; ANDRADE, Paulo Fernando Carneiro de (org.). Decolonialidade e práticas emancipatórias: novas perspectivas para a área de Ciências da Religião e Teologia, São Paulo: Paulinas, 2019.

51 Usamos este termo porque existem acordos entre os poderes financeiros e empresariais e as forças politicas a eles atrelados, comparáveis aos pactos coloniais comerciais do passado entre as potências colonizadoras. Cf. TEIXEIRA Jr., Luiz Alexandre. O engenho colonial: cotidiano da história. São Paulo: Ática, 1990; FAUSTO, Boris. História do Brasil. São Paulo: EDUSP, 1995.
} 
Hermenêutica bíblica da Teologia da Libertação Johan Konings

co de orientação descolonial não se contenta com uma crítica das estruturas socioeconômicas "objetivas", mas procura aprofundar a libertação “subjetiva”, cultural e mental, o que, não sem causa, tem provocado nítidas reações anti-intelectuais nos que almejam a hegemonia e, aventando até pretextos religiosos, não desejam que o povo pense. É preciso ação e conscientização voltadas para a subjetividade, ${ }^{52}$ tanto coletiva como pessoal, pois o coletivo é feito de pessoas. Será preciso mostrar que a liberdade cristã deve estar radicada no coração e na mente das pessoas, tornando verdadeira a palavra de Cristo: "A verdade vos libertará" (Jo 8,32). Segundo o processo de hermenêutica acima explicado, as analogias bíblicas ajudam a perceber a raiz profunda desse conflito, sobretudo a luta profética contra a idolatria e as palavras de Jesus denunciando o "servir a dois senhores" (Mt 6,24\|LC 16,13).

Quanto à hermenêutica ecológica, a dimensão "libertadora" se encontra, por exemplo, nas orientações do Papa Francisco a respeito do cuidado da "casa comum". ${ }^{53}$ Ele sugere juntar cientistas e jovens para pedir, especialmente àqueles em posições de poder político e econômico, que tomem medidas drásticas para mudar de rumo. ${ }^{54}$ Devemos "pensar num único mundo, num projeto comum" (FRANCISCO, 2015, n. 164), ${ }^{55}$ em sentido oposto à exploração egoísta e irresponsável, que nem é preciso descrever e que ultimamente vem embutida em certa visão pretensamente liberal, o Papa urge um estudo do impacto ambiental que preceda os planos desenvolvimentistas. "Há-de inserir-se desde o princípio e elaborar-se de forma interdisciplinar, transparente e independente de qualquer pressão econômica ou política". ${ }^{56}$ Pode-se observar certa imprecisão nesta frase, pois a própria instauração de um estudo do impacto ambiental é uma decisão política no sentido

\footnotetext{
52 A guinada para a análise da subjetividade coletiva reforçará o caráter latino-americano e africano da Teologia da Libertação, que na sua primeira fase foi ainda muito devedora à análise socioeconômica e política de origem europeia.

53 Cf. BOFF, Leonardo. O cuidado necessário: na vida, na saúde, na educação, na ecologia, na ética e na espiritualidade. 2.ed. Petrópolis: Vozes, 2013. MURAD, Afonso; TAVARES, Sinivaldo Silva (org.) Cuidar da casa comum: chaves de leitura teológicas e pastorais da Laudato Si'. São Paulo: Paulinas, 2016.

54 Este projeto se realizará nos próximos dias 26 a 28 de março de 2020, no encontro mundial para repensar a economia global (sítio francescoeconomy.org).

55 Este pensamento dimensão ecumênica, como parece na concórdia entre o Papa Francisco e o Patriarca de Constantinopla, Bartolomeu I, sumamente empenhado na causa ecológica.

56 Ibid., n. 183.
} 
Hermenêutica bíblica da Teologia da Libertação Johan Konings

nobre deste termo. Mas a intenção do Papa contém um elemento libertador: preservar a liberdade em relação a políticas parciais e interesseiras promovidas sem (suficiente) consideração ou até com desprezo pela "casa comum". Assim, o Papa vai de encontro não só da visão tecnicista - a ilusão da superação pela tecnologia, que chega a considerar o próprio planeta em certo sentido descartável -, mas também do anti-humanismo de certos ecologistas, que consideram a atual evolução como a inevitável aproximação da extinção da humanidade, "câncer do universo" como às vezes é chamada.

A extinção da humanidade não é um tabu em que nem se pode pensar. A Ciência e a ficção científica nos fazem pensar que nosso ambiente humano não é para sempre. Porém, a questão que nos ocupa não é o futuro indefinido do universo, mas a vida humana digna nos próximos séculos, projetada a partir do nosso hoje. O mundo que deixaremos para as gerações depois de nós. Se quisermos que "nossa casa comum" seja uma casa de irmãs e irmãos, é necessária uma reflexão teológica "libertadora" para resistir à manipulação e exploração mortífera que ameaça com perigos graves e iminentes o habitat humano, animal e vegetal. Diz Fritjof Capra a respeito do diálogo entre Leonardo Boff e Mark Hathaway: "Eles escrevem que 'de uma maneira muito real, nós somos chamados a nos reinventar como espécie'. Eles se referem a este processo de profunda transformação como 'libertação', na mesma maneira em que este termo é usado na tradição de Teologia da Libertação; quer dizer, no nível pessoal como forma de realização ou iluminação espiritual e no nível coletivo como a procura de um povo de se libertar de opressões". ${ }^{57}$

É preciso conceber-nos como "cuidadores", ao contrário do capitalismo predador que pensa: "Aprés nous, le déluge". ${ }^{58}$ No sentido oposto, a tradição bíblica e cristã culmina na nova Jerusalém e na nova criação. A libertação da criação faz parte da "utopia cristã"

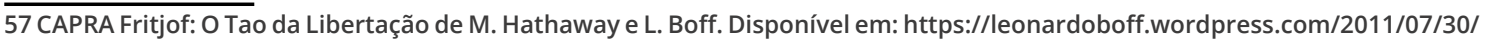
fritjof-capra-o-tao-da-libertacao-de-m-hathaway-e-I-boff/. Acesso em: 27 set. 2017.

58 Frase atribuída ora a Luís XV da França, ora a sua amante Mme. de Pompadour. 
Hermenêutica bíblica da Teologia da Libertação

Johan Konings

$(\mathrm{Rm} 8,22)$. Não esqueçamos que o Canto na Fogueira ${ }^{59}$ é também um Cântico das Criaturas. ${ }^{60}$

\section{Concluindo}

Esta evocação da hermenêutica da libertação é altamente incompleta, mas de toda maneira mostra que o escopo desse afazer teológico não está superado, embora o acento possa se deslocar e o nome, eventualmente, modificar-se. Pelo contrário, percebemos que a "liberdade", significando a dignidade e o reconhecimento de todas as pessoas, a começar pelas mais deserdadas, está fortemente ameaçada em nossos dias. E não se trata de uma questão só das pessoas humanas, individual ou coletivamente, mas de todo o ambiente da humanidade, a "casa comum". A análise da sociedade deve ter consciência do novo pacto colonial e não se iludir quanto à solidez duradoura da liberdade proclamada em séculos anteriores. Os paradigmas de leitura bíblica deverão ser ampliados e incluir a teologia da criação, e o esforço hermenêutico, a "tradução na tradição" não pode esmorecer diante de fundamentalismos ora ingênuos, ora servindo a interesses escusos - ou ambas as coisas. E todo esse esforço, da parte de quem for cristão, seja marcado pelo critério decisivo: "em Cristo". ${ }^{61}$

\section{Referências}

A BÍBLIA SAGRADA Antigo e Novo Testamento. Traduzida em Português por João Ferreira de Almeida. Ed. revista e atualizada no Brasil. Rio de Janeiro: Sociedade Bíblica do Brasil, 1969.

ASLAN, Reza. Zelota: a vida e a época de Jesus de Nazaré. Rio de Janeiro: Zahar, 2013.

\footnotetext{
59 Título do livro de Fernando de Brito (com Frei Betto e Ivo Lesbaupin) sobre a prisão no regime militar no Brasil pós-1964 (0 canto na fogueira. Petrópolis: Vozes, 1977).

600 Canto na Fogueira, em Daniel 3,26-45 (LXX), poema deuterocanônico posto na boca de Azarias (o Abdênago de Dn 3,12-23), é uma prece de arrependimento e esperança. O Cântico das Criaturas, que lhe segue, entoado pelos três jovens (Dn 3,52-90 LXX), é um louvor ao Deus "dos nossos pais" (v. 52), o "Deus dos deuses" (v. 90), dando voz a todas as criaturas na aclamação geral. o Cântico do Sol de Francisco de Assis se inspirou neste texto de exímia beleza.

61 Sem negligenciar o diálogo com quem lê a Bíblia na delimitação judaica.
} 
BEALE, David O. In Pursuit of Purity: American Fundamentalism Since 1850. Greenville, SC: Unusual Publications, 1986. Disponível em: http://www.thearda.com/timeline/events/event_93.asp. Acesso em: 27 set. 2019.

BEOZZO, José Oscar. Pacto das Catacumbas: por uma Igreja servidora e pobre. São Paulo: Paulinas, 2016.

BLOCH, Ernst. O princípio esperança. Rio de Janeiro: EDUERJ, 2005-2006. 3 v.

BOFF, Leonardo. O cuidado necessário: na vida, na saúde, na educação, na ecologia, na ética e na espiritualidade. 2.ed. Petrópolis: Vozes, 2013.

BOFF, Leonardo; HATHAWAY, Mark. O Tao da Libertação. Petrópolis: Vozes, 2012.

CAPRA Fritjof. Fritjof Capra: o Tao da Libertação de M. Hathaway e L. Boff. In: BOFF, Leonardo. Blog Leonardo Boff. Rio de Janeiro, 22 de abril de 2009. Disponível em: https://leonardoboff. org/2011/07/30/fritjof-capra-o-tao-da-libertacao-de-m-hathaway-e-l-boff/. Acesso em: 27 set. 2019.

CROATTO, Severino José. Hermenêutica bíblica: para uma teoria da leitura como produção de significado. São Leopoldo: Sinodal, 1986.

CROATTO, Severino José. Êxodo: uma hermenêutica da liberdade. São Paulo: Paulinas, 1981.

CROSSAN, John Dominic. O Jesus histórico: a vida de um camponês judeu do Mediterrâneo. Rio de Janeiro: Imago, 1994.

FAUSTO, Boris. História do Brasil. São Paulo: EDUSP, 1995.

FRANCISCO, Papa. Carta encíclica Laudato Si' do Santo Padre Francisco sobre o cuidado da casa comum. São Paulo: Loyola, 2015.

GADAMER, Hans-Georg. Verdade e método I: traços fundamentais de uma hermenêutica filosófica. 4.ed. Petrópolis: Vozes, 2002. 
GADAMER, Hans-Georg. Verdade e método II: complementos e índice. Petrópolis: Vozes, 2002.

INTROVIGNE, Massimo. O fundamentalismo: das origens ao Estado Islâmico. São Paulo: Loyola, 2019.

KONINGS, Johan. Fundamentalismo bíblico-teológico-religioso. In: MILLEN, Maria Inês de Castro; ZACHARIAS, Ronaldo (org.). Fundamentalismo: desfaio à ética teológica. Aparecida SP: Santuário, 2017, p. 173-174.

KUZMA, César; ANDRADE, Paulo Fernando Carneiro de (org.). Decolonialidade e práticas emancipatórias: novas perspectivas para a área de Ciências da Religião e Teologia, São Paulo: Paulinas, 2019.

LUBAC, Henri de. A Escritura na tradição. São Paulo: Paulinas, 1970.

MESTERS, Carlos. Por trás das palavras: um estudo sobre a porta de entrada no mundo da Biblia. 2. ed. Petrópolis: Vozes, 1975 MESTERS, Carlos. Flor sem defesa: uma explicação da Bíblia a partir do povo. 3. ed. Petropolis: Vozes, 1986.

MIGNOLO, Walter D. La idea de América Latina: la herida colonial y la opción decolonial. Barcelona: Gedisa, 2014.

MILLEN, Maria Inês de Castro; ZACHARIAS, Ronaldo (org.).

Fundamentalismo: desfaio à ética teológica. Aparecida SP:

Santuário, 2017.

MOLTMANN, Jürgen. El Dios crucificado: la cruz de Cristo como base y crítica de toda teología cristiana. Salamanca: Sigueme, 1975.

MOLTMANN, Jürgen. O caminho de Jesus Cristo: cristologia em dimensões messiânicas. Petropolis: Vozes, 1993.

MURAD, Afonso; TAVARES, Sinivaldo Silva (org.). Cuidar da casa comum: chaves de leitura teológicas e pastorais da Laudato Si'. São Paulo: Paulinas, 2016. 
Hermenêutica bíblica da Teologia da Libertação

PONTIFÍCIA COMISSÃO BÍBLICA. A interpretação da Bíblia na Igreja: discurso de sua santidade o papa João Paulo II e documento da Pontifícia Comissão Bíblica. 7. ed. São Paulo: Paulinas, 2006.

REIMER, Haroldo; SILVA, Valmor da (org.). Hermenêuticas bíblicas: contribuições ao I Congresso Brasileiro de Pesquisa Bíblia. São Leopoldo: Oikos, 2006.

RICOEUR, Paul. O conflito das interpretações: ensaios de hermenêutica. Rio de Janeiro: Imago, 1978.

SCHWEIZER, Eduard. Orthodox Proclamation: The Reinterpretation of the Gospel by the Fourth Evangelist. Union Seminary Magazine, v. 8, n. 4, p. 387-403, Oct. 1954. Disponível em: https://doi.org/10.1177/002096435400800401. Acesso em: 11 jul. 2019.

SOBRINO, Jon. Cristologia a partir da America Latina: esboço a partir do seguimento do Jesus histórico. Petrópolis: Vozes, 1983.

TEIXEIRA Jr., Luiz Alexandre. O engenho colonial: cotidiano da história. São Paulo: Ática, 1990.

TORRES QUEIRUGA, Andrés. Do terror de Isaac ao Abbá de Jesus: por uma nova imagem de Deus. São Paulo: Paulinas, 2001. VERGOTE, Antoon. Liberare dio, liberare l'uomo. Assisi: Cittadella, 1977. 